\title{
Phase 1 study of ixazomib, an investigational proteasome inhibitor, in advanced non-hematologic malignancies
}

\author{
David C. Smith • Thea Kalebic • Jeffrey R. Infante • \\ Lillian L. Siu • Daniel Sullivan • Gordana Vlahovic • \\ John S. Kauh • Feng Gao • Allison J. Berger • \\ Stephen Tirrell • Neeraj Gupta • Alessandra Di Bacco • \\ Deborah Berg • Guohui Liu • Jianchang Lin • \\ Ai-Min Hui • John A. Thompson
}

Received: 10 December 2014 / Accepted: 6 March 2015 /Published online: 18 March 2015

(C) The Author(s) 2015. This article is published with open access at Springerlink.com

Summary Purpose Ixazomib is an investigational proteasome inhibitor with demonstrated antitumor activity in xenograft models of multiple myeloma (MM), lymphoma, and solid tumors. This open-label, phase 1 study investigated intravenous (IV) ixazomib, in adult patients with advanced non-

Electronic supplementary material The online version of this article (doi:10.1007/s10637-015-0230-x) contains supplementary material, which is available to authorized users.

\section{C. Smith $(\bowtie)$}

University of Michigan Comprehensive Cancer Center, 7302 CC SPC 5948, 1500 E. Medical Center Drive, Ann

Arbor, MI 48109-5948, USA

e-mail: dcsmith@umich.edu

T. Kalebic $\cdot$ F. Gao $\cdot$ A. J. Berger $\cdot$ S. Tirrell $\cdot$ N. Gupta $\cdot$

A. Di Bacco · D. Berg · G. Liu · J. Lin · A.-M. Hui

Takeda Pharmaceuticals International Co., Cambridge, MA, USA

J. R. Infante

Sarah Cannon Research Institute, Nashville, TN, USA

\section{L. Siu}

Princess Margaret Hospital, Toronto, ON, Canada

D. Sullivan

H. Lee Moffitt Cancer Center and Research Institute, Tampa, FL, USA

G. Vlahovic

Duke Comprehensive Cancer Center, Durham, NC, USA

\section{J. S. Kauh}

Winship Cancer Institute of Emory University, Atlanta, GA, USA

\section{J. A. Thompson}

Seattle Cancer Care Alliance, Seattle, WA, USA hematologic malignancies. Methods Patients received IV ixazomib twice-weekly for up to twelve 21-day cycles. The $0.125 \mathrm{mg} / \mathrm{m}^{2}$ starting dose was doubled (one patient/dose) until $1.0 \mathrm{mg} / \mathrm{m}^{2}$ based on dose-limiting toxicities (DLTs) in cycle 1 . This was followed by $3+3$ dose-escalation and expansion at the maximum tolerated dose (MTD). Primary objectives included safety and MTD assessment. Secondary objectives included assessment of pharmacokinetics, pharmacodynamics, and disease response. Results Ixazomib was escalated from 0.125 to $2.34 \mathrm{mg} / \mathrm{m}^{2}$ to determine the MTD $(n=$ $23)$; patients were then enrolled to MTD expansion $(n=73)$ and pharmacodynamic $(n=20)$ cohorts. Five patients experienced DLTs $\left(1.0\right.$ and $1.76 \mathrm{mg} / \mathrm{m}^{2}$ : grade 3 pruritic rash; $2.34 \mathrm{mg} / \mathrm{m}^{2}$ : grade 3 and 4 thrombocytopenia, and grade 3 acute renal failure); thus, the MTD was $1.76 \mathrm{mg} / \mathrm{m}^{2}$. Drugrelated grade $\geq 3$ adverse events (AEs) included thrombocytopenia $(23 \%)$, skin and subcutaneous (SC) tissue disorders (16\%), and fatigue (9\%). Among 92 evaluable patients, one (head and neck cancer) had a partial response and 30 had stable disease. Ixazomib terminal half-life was 3.8-7.2 days; plasma exposures increased doseproportionally and drug was distributed to tumors. Inhibition of whole-blood 20S proteasome activity and upregulation of ATF-3 in tumor biopsies demonstrated target engagement. Conclusions In patients with solid tumors, ixazomib was associated with a manageable safety profile, limited antitumor activity, and evidence of downstream proteasome inhibition effects.

Keywords $20 \mathrm{~S}$ proteasome - Activating transcription factor 3 - Ixazomib · Non-hematologic malignancies · Phase 1 clinical trial (4-6) 


\section{Introduction}

The ubiquitin-proteasome system is a key pathway for protein degradation and as such plays a key role in protein homeostasis $[1,2]$. Clinically, bortezomib has shown proteasome inhibition to be a highly promising treatment strategy for multiple myeloma (MM) and other hematologic malignancies [3-6]. Despite the proven efficacy in hematologic malignancies, clinical activity is limited in solid tumors [7-13]. Preclinical data; however, implied the potential for antitumor effects in solid tumor models [14-18]. It has been suggested that a lack of drug penetration into the tumor may be the cause of this modest antitumor activity $[19,20]$.

The investigational agent ixazomib is an orally bioavailable, small molecule, potent, reversible, and selective inhibitor of the $\beta 5$ site of the $20 \mathrm{~S}$ proteasome, which is structurally different from bortezomib [20]. Ixazomib is currently being investigated in phase 3 trials in MM (Clinicaltrials.gov identifiers NCT01564537 and NCT01850524) and primary systemic AL amyloidosis (NCT01659658). When compared with bortezomib, ixazomib demonstrated faster dissociation from the proteasome in vitro, and data from mouse xenograft models of human cancers suggested increased proteasome inhibition in tumor tissue [20]. Preclinical studies also demonstrated the antiproliferative activity of ixazomib in tumor cell lines with potent antitumor activity in xenograft models of MM, lymphoma, and some solid tumors [20-22]. These data provided the rationale for the clinical development of ixazomib in both hematologic and non-hematologic malignancies. In clinical trials conducted to date, ixazomib was studied as an intravenous (IV) formulation, initially, and subsequently as an oral formulation.

This paper reports the results of the first-in-human, phase 1 dose-escalation study (NCT00830869) of twice-weekly IV ixazomib in patients with advanced solid tumors. The study included a drug distribution and pharmacodynamic assessment of activating transcription factor-3 (ATF-3) levels in solid tumor tissue as a marker of target engagement and an evaluation of whole blood 20S proteasome activity.

\section{Materials and methods}

\section{Patients}

Eligible participants were aged $\geq 18$ years with a diagnosis of a non-hematologic malignancy for which standard treatment was no longer effective or did not offer curative or lifeprolonging potential. Eastern Cooperative Oncology Group (ECOG) performance status of $0-2$, absolute neutrophil count (ANC) $\geq 1,500 / \mathrm{mm}^{3}$, platelet count $\geq 100,000 / \mathrm{mm}^{3}$, total bilirubin $\leq 1.5 \times$ the upper limit of normal (ULN), alanine aminotransferase (ALT) and aspartate aminotransferase (AST) $\leq 2.5 \times$ ULN $(\leq 5 \times$ ULN if the elevation can be reasonably ascribed to metastatic disease), creatinine clearance or calculated creatinine clearance $\geq 60 \mathrm{~mL} / \mathrm{min}$, and QTc $<470 \mathrm{~ms}$ on 12 lead electrocardiogram were required. Patients also had no: peripheral neuropathy (PN) of grade $\geq 2$; diarrhea of grade $>1$; recent $(<14$ days) major surgery; infection requiring systemic antibiotic therapy; symptomatic brain metastasis; uncontrolled cardiovascular conditions within the past 6 months; radiotherapy or systemic antineoplastic therapy within 21 days; or any investigational products within 28 days before the first dose. In the disease-specific expansion and tumor pharmacodynamic expansion (TPEC) cohorts, radiographically or clinically evaluable tumor (clinically measurable disease per Response Evaluation Criteria in Solid Tumors [RECIST]) was required. An elevated prostate specific antigen (PSA) level alone per modified Prostate Cancer Working Group 2 (PCWG2) criteria was acceptable for evaluation of prostate cancer.

All patients provided written informed consent and were free to withdraw at any time during the study. Institutional Review Boards at all participating institutions approved the study and the informed consent documents. The study was conducted according to the provisions of the Declaration of Helsinki, the International Conference on Harmonization, and Guidelines for Good Clinical Practice.

\section{Study design}

This open-label, non-randomized, dose-escalation phase 1 study was conducted at 7 sites in the United States and Canada, with patients enrolled from March 02, 2009 to January 10,2012 . The primary objective of the trial was to determine the safety profile, establish the maximum tolerated dose (MTD), and inform the recommended phase 2 dose of IV ixazomib in patients with non-hematologic malignancies. Secondary objectives were to characterize the pharmacokinetics and pharmacodynamics of IV ixazomib in blood and to evaluate disease response. Drug distribution and target engagement in post-dose tumor samples was measured by determining the increase in ATF-3 levels in post-dose tumor samples compared with pre-dose samples by immunohistochemistry (IHC).

Patients received ixazomib as an IV bolus on days $1,4,8$, and 11 of a 21-day cycle, for up to 12 cycles, or until disease progression or unacceptable toxicity. Patients who were thought to potentially benefit from prolonged therapy could receive continued treatment beyond 12 cycles according to the treating physician's consideration. Patients could receive prophylactic antiviral therapy; prophylactic antidiarrheals and antiemetics were not employed initially but could be considered upon development of diarrhea or nausea/vomiting.

The dose-escalation cohort comprised patients with any non-hematologic malignancy. The four MTD expansion 
cohorts were limited to patients with non-small cell lung cancer (NSCLC), head and neck cancer (squamous cell cancer), soft tissue sarcoma, and prostate cancer, respectively. In addition, the TPEC was open to patients with non-hematologic malignancy that could be safely biopsied. Dose escalation initially proceeded from a starting dose of $0.125 \mathrm{mg} / \mathrm{m}^{2}$ of body surface area, with one patient per dose level and dose doubling up to a dose of $1.0 \mathrm{mg} / \mathrm{m}^{2}$. Dose doubling was permitted until one of the following occurred: one patient experienced a dose-limiting toxicity (DLT) during cycle 1; any two patients experienced a drug-related adverse event (AE) of grade $\geq 2$ during cycle 1 ; or the dose level of $1 \mathrm{mg} / \mathrm{m}^{2}$ had been evaluated. Dose escalation then proceeded in $33 \%$ increments following a standard $3+3$ schema based on the occurrence of DLTs in cycle 1. DLTs were defined as any of the following: grade 4 neutropenia or thrombocytopenia lasting for $>7$ consecutive days, or a platelet count of $<10,000 / \mathrm{mm}^{3}$ at any time; grade 3 neutropenia with infection/fever or thrombocytopenia with clinically significant bleeding; grade $\geq 3 \mathrm{PN}$; grade 3 QTc prolongation; any other grade $\geq 3$ nonhematologic toxicity (despite optimal antiemetic prophylaxis for nausea/emesis and supportive therapy for diarrhea), except grade 3 arthralgia/myalgia or short-term $(<1$ week) grade 3 fatigue; a delay of $>1$ week in commencing cycle 2 due to lack of adequate recovery of ixazomib-related toxicities; or other grade $\geq 2$ ixazomib-related toxicities requiring discontinuation in the opinion of the investigator. The MTD was defined as the highest dose level at which $0 / 3$ or $1 / 6$ patients experienced DLTs during cycle 1 . Once the MTD had been established, patients (including those from the dose-escalation cohort meeting the eligibility criteria) were enrolled into four MTD expansion cohorts and the TPEC, as defined above.

\section{Assessments}

AEs were monitored throughout the study and were graded according to National Cancer Institute Common Terminology Criteria for Adverse Events (NCI-CTCAE) v3.0. Response assessments were undertaken by investigators using a consistent imaging modality in accordance with RECIST 1.0 [23] on days 18-21 of cycle 2 and subsequent cycles. For patients with prostate cancer, response and progressive disease were based on RECIST for measurable neoplastic disease [23] or on measurement of serum PSA per modified PCWG2 criteria in the absence of measurable sites [24].

Blood samples for determination of plasma ixazomib concentrations for pharmacokinetic analysis $(3 \mathrm{~mL})$ and for measurement of whole blood $20 \mathrm{~S}$ proteasome activity $(1 \mathrm{~mL})$ were collected at the following timepoints for all patients in the dose-escalation cohort and for the first 12 patients completing cycle 1 while receiving protocol-specified treatment at the MTD: pre-dose (within $1 \mathrm{~h}$ ) on days 1, 4, 8, and 11 of cycle 1 , and on day 1 of cycle 2 ; and on days 1 and 11 , cycle 1 , at 5 ,
15 and 30 min, and 1, 2, 4, 9, 24, 48, 96 (day 11 only), 120 (day 11 only), and 168 (day 11 only) h post-dose. A limited sampling schedule was employed for the remaining patients in the MTD expansion cohorts.

Plasma concentrations of ixazomib were measured using a good laboratory practice-validated liquid chromatography/ tandem mass spectrometry (LC/MS/MS) assay with a lower limit of quantification of $0.5 \mathrm{ng} / \mathrm{mL}$. Whole blood $20 \mathrm{~S}$ proteasome activity (expressed as percent proteasome inhibition relative to baseline) was measured using an established fluorogenic assay [25], which evaluates the chymotrypsinlike activity of the $\beta 5$ subunit of the $20 \mathrm{~S}$ proteasome, the primary target of ixazomib.

Tumor biopsies were analyzed for the presence of ixazomib using a quantified LC/MS/MS methodology validated in xenograft models. Expression of ATF-3 was measured in the TPEC using an IHC staining assay developed and validated using preclinical and human primary tumor samples. For this assay, formalin-fixed, paraffin-embedded tumor biopsy samples were obtained pre- and post-treatment (at 4-24 h postdosing on day 1 or day 4 of cycle 1). Six $5 \mu \mathrm{m}$ sections from each tumor sample were then cut $(10 \mu \mathrm{m}$ apart) and stained with antibody to ATF-3 (Santa Cruz Biotechnology, Inc., sc188, lot:K1908) on a Discovery XT autostainer (Ventana Medical Systems, Inc.). After staining, whole slides were scanned and analyzed to calculate the percentage ATF-3positive area for each section using the Genie ${ }^{\mathrm{TM}}$ (Aperio ${ }^{\circledR}$ ePathology Solutions) pattern recognition tool. The ATF-3positive area was measured within the tumor region using the Positive Pixel Count algorithm, and the percentage ATF3-positive area/total tumor area was then calculated for each section.

\section{Statistical analyses}

The safety population included all patients who received $\geq 1$ dose of ixazomib, and the DLT-evaluable population, which was used for determination of the MTD, comprised patients who received all cycle 1 doses of ixazomib or experienced a DLT in cycle 1 . The pharmacokinetic and pharmacodynamic populations included all patients in the dose-escalation cohort and the first 12 patients treated at the MTD who did not receive any excluded concomitant medications during the time of blood sampling, and who had sufficient concentration-time or effect-time data to permit reliable estimation of pharmacokinetic/pharmacodynamic parameters. The response-evaluable population included all patients who received $\geq 1$ dose of ixazomib, had measurable disease at baseline, and had $\geq 1$ post-baseline disease assessment. Approximately 16 response-evaluable patients were planned to be evaluated in each MTD expansion cohort. The binomial probability calculation showed that if the overall response rate was $10 \%$, there was approximately an $81 \%$ probability of 


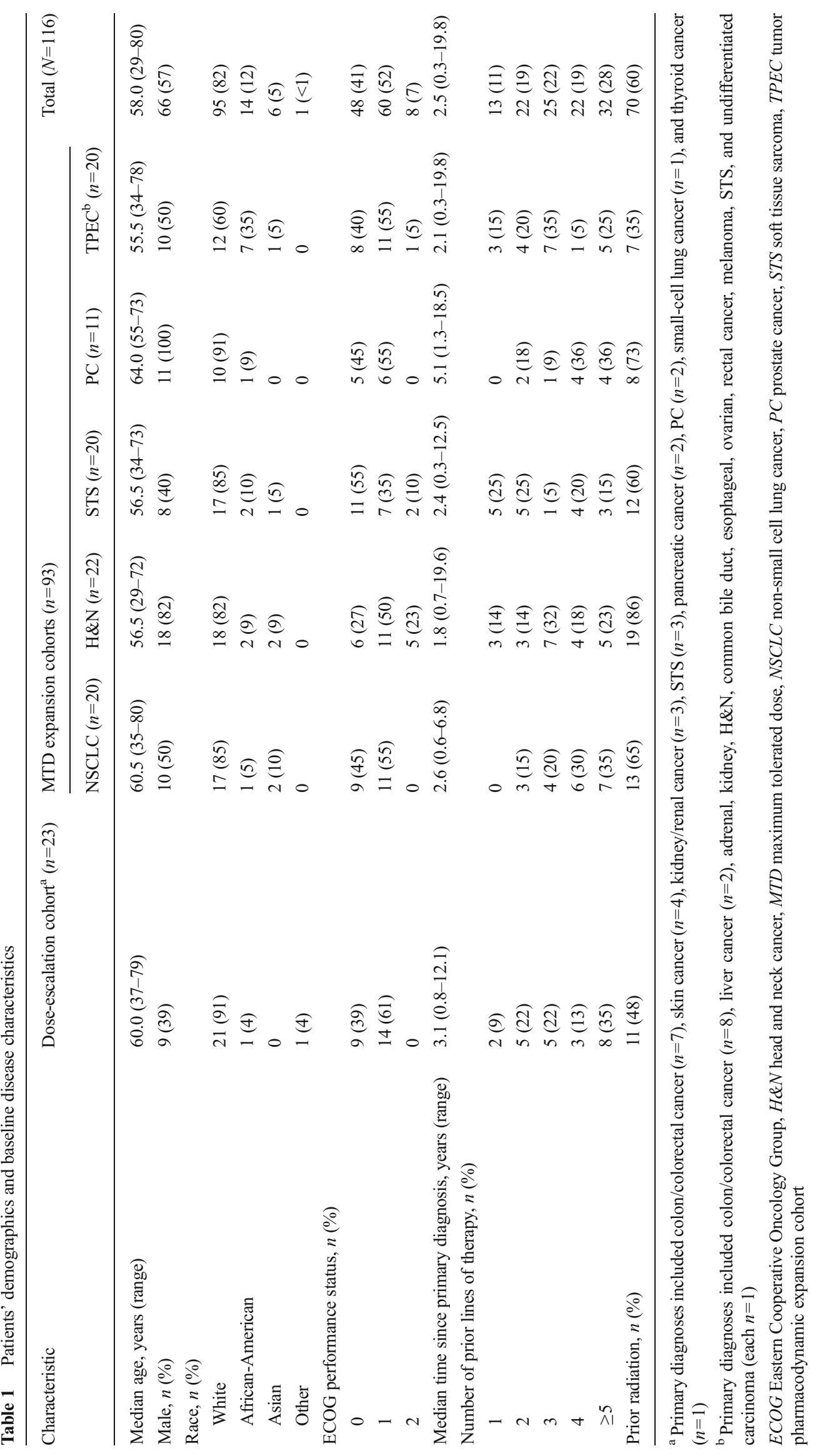


observing $\geq 1$ response and a $49 \%$ probability of observing $\geq 2$ responses in 16 patients.

All efficacy and safety data were summarized using descriptive statistics. Pharmacokinetic and pharmacodynamic parameters were calculated using noncompartmental methods (WinNonlin software v5.3).

Approximately 16 patients were planned to be enrolled to the TPEC to estimate ixazomib concentrations in tumors and target engagement as ATF-3 expression levels. A survey of human tumors on tissue microarrays, some with multiple tumor samples derived from the same individual, was performed to evaluate between-subject and within-subject variability in the ATF-3-positive area. A mixed-effect model using data from all evaluable pre- and post-dose samples estimated a within-subject coefficient of variation of $28.33 \%$. This value was used to determine the minimum number of sections $(n=6)$ for pharmacodynamic analysis and the size of the fold change in ATF-3 that could be detected with $80 \%$ power. Student's ttests on individual patient data were used to determine the number of patients with a significant fold increase $(p<0.05)$ in ATF-3 after ixazomib treatment.

\section{Results}

\section{Patients}

A total of 116 patients were enrolled in this study. Twentythree patients were enrolled to the dose-escalation cohort, including: one patient each at $0.125,0.25$, and $0.5 \mathrm{mg} / \mathrm{m}^{2}$; seven patients at $1 \mathrm{mg} / \mathrm{m}^{2}$; four patients at $1.33 \mathrm{mg} / \mathrm{m}^{2}$; six patients at $1.76 \mathrm{mg} / \mathrm{m}^{2}$; and three patients at $2.34 \mathrm{mg} / \mathrm{m}^{2}$. Seventythree patients were enrolled to the MTD expansion cohorts, including 20 with NSCLC, 22 with head and neck cancer, 20 with soft tissue sarcoma, and 11 with prostate cancer. A total of 20 patients were enrolled to the TPEC.

Patients' demographics and baseline disease characteristics are summarized in Table 1. Patients had received a median of 3 prior lines of therapy (range, 1 to $>4$ ) and median time since primary diagnosis among all patients was 2.5 years.

\section{DLTs and determination of MTD}

Of the 23 patients enrolled in the dose-escalation phase, 22 received all doses of ixazomib during cycle 1 and either completed the cycle or developed a DLT during the cycle; these 22 patients were included in the DLT-evaluable population. One patient died from progressive thyroid cancer and did not receive their day 11 dose, and hence was not DLT-evaluable.

Five patients experienced DLTs. One patient treated at the $1.0 \mathrm{mg} / \mathrm{m}^{2}$ dose level reported a DLT of grade 3 pruritic rash. Ixazomib dosing was held for this patient and, following administration of concomitant medication, the rash resolved within 10 days and the patient continued at a lower dose. At the $1.76 \mathrm{mg} / \mathrm{m}^{2}$ dose level, one patient reported a DLT of grade 3 pruritic rash, which persisted despite reducing and holding the dose of ixazomib; therapy was subsequently discontinued. The patient was treated with hydroxyzine, methylprednisolone, and diphenhydramine, and the pruritic rash resolved after 42 days. DLTs reported in three patients treated at the ixazomib $2.34 \mathrm{mg} / \mathrm{m}^{2}$ dose level were: grade 4 thrombocytopenia; grade 3 thrombocytopenia with grade 1 rectal hemorrhage; and grade 3 acute renal failure (pre-renal azotemia associated with nausea, vomiting, diarrhea, and dehydration). The patient with grade 4 thrombocytopenia was hospitalized, and the ixazomib dose was delayed and reduced. The patient with grade 3 thrombocytopenia with grade 1 rectal hemorrhage was admitted to hospital and subsequently died due to progressive disease before the next dose of study drug was to be administered. The patient with grade 3 acute renal failure was hospitalized and ixazomib was permanently discontinued. The MTD of ixazomib was thus determined to be $1.76 \mathrm{mg} / \mathrm{m}^{2}$ administered on days $1,4,8$, and 11 of a 21 day cycle. Patients enrolled to the MTD expansion cohorts and the TPEC were treated at this dose of ixazomib.

\section{Treatment exposure and safety profile}

Patients received a median of 2 treatment cycles (range, 1 to 12) overall, and across all individual cohorts. The maximum number of cycles received varied by cohort: the maximum number of cycles was $10,8,12,7,4$, and 4 cycles in the dose-escalation, NSCLC, head and neck cancer, soft tissue sarcoma, and prostate cancer cohorts, and the TPEC, respectively. Overall, 23 patients ( $20 \%$ ) received $\geq 4$ cycles; 22 of 99 patients $(22 \%)$ treated at the MTD received $\geq 4$ cycles of therapy. Mean ixazomib dosing compliance (percent total dose received/total dose expected during time on treatment) was $97.9 \%$ overall, and was similar across cohorts.

All 116 patients received $\geq 1$ dose of ixazomib and were included in the safety population. Of these patients, $115(99 \%)$ experienced $\geq 1$ treatment-emergent $\mathrm{AE}$ and 104 (90\%) experienced $\geq 1$ drug-related AE (Supplementary Table 1). The most common drug-related AEs are summarized in Table 2. A total of 84 patients $(72 \%)$ had $\geq 1$ treatment-emergent grade $\geq 3 \mathrm{AE} ; 66$ patients $(57 \%)$ had $\geq 1$ drug-related grade $\geq 3$ AE. The most common drug-related grade $\geq 3$ AEs are shown in Table 3 .

Treatment-related skin and subcutaneous (SC) tissue disorders (reported under the MedDRA System Organ class), which were the most common drug-related AEs overall, were observed in 61 patients $(53 \%)$. These were grade 3 in 18 patients $(16 \%)$ and included two of the DLTs. Rash had resolved by the end of the study in all but two cases. There was no grade 4 rash. Duration of rash ranged from 4 to 90 days (median 15 days). Ten patients received IV or oral corticosteroids with or without antihistamine, four patients received IV 
Table 2 The most common ( $\geq 10 \%$ of patients overall) drug-related AEs, overall and within the dose-escalation and expansion cohorts

\begin{tabular}{|c|c|c|c|c|c|c|c|}
\hline \multirow[t]{2}{*}{$\mathrm{AE}, n(\%)$} & \multirow{2}{*}{$\begin{array}{l}\text { Dose-escalation cohort } \\
(n=23)\end{array}$} & \multicolumn{5}{|c|}{ MTD expansion cohorts $(n=93)$} & \multirow{2}{*}{$\begin{array}{l}\text { Total } \\
(N=116)\end{array}$} \\
\hline & & $\begin{array}{l}\text { NSCLC } \\
(n=20)\end{array}$ & $\begin{array}{l}\mathrm{H} \& \mathrm{~N} \\
(n=22)\end{array}$ & $\begin{array}{l}\text { STS } \\
(n=20)\end{array}$ & $\begin{array}{l}\mathrm{PC} \\
(n=11)\end{array}$ & $\begin{array}{l}\text { TPEC } \\
(n=20)\end{array}$ & \\
\hline Skin and SC tissue disorders ${ }^{\mathrm{a}}$ & $7(30)$ & $9(45)$ & $12(55)$ & $12(60)$ & $9(82)$ & $12(60)$ & $61(53)$ \\
\hline Fatigue & $8(35)$ & $11(55)$ & $11(50)$ & $8(40)$ & $7(64)$ & $10(50)$ & $55(47)$ \\
\hline Thrombocytopenia & $6(26)$ & $8(40)$ & $11(50)$ & $8(40)$ & $6(55)$ & $13(65)$ & $52(45)$ \\
\hline Nausea & $7(30)$ & $8(40)$ & $9(41)$ & $4(20)$ & $4(36)$ & $9(45)$ & $41(35)$ \\
\hline Decreased appetite & $7(30)$ & $6(30)$ & $5(23)$ & $5(25)$ & $4(36)$ & $11(55)$ & $38(33)$ \\
\hline Vomiting & $5(22)$ & $8(40)$ & $7(32)$ & $6(30)$ & $2(18)$ & $8(40)$ & $36(31)$ \\
\hline Diarrhoea & $4(17)$ & $6(30)$ & $7(32)$ & $5(25)$ & 0 & $5(25)$ & $27(23)$ \\
\hline $\begin{array}{l}\text { Peripheral neuropathies } \\
\text { NEC }^{\mathrm{b}}\end{array}$ & $2(9)$ & $2(10)$ & $1(5)$ & $5(25)$ & $3(27)$ & $4(20)$ & $17(15)$ \\
\hline Pyrexia & 0 & $5(25)$ & $2(9)$ & $5(25)$ & 0 & $4(20)$ & $16(14)$ \\
\hline Stomatitis & 0 & $3(15)$ & $3(14)$ & $4(20)$ & $2(18)$ & $2(10)$ & $14(12)$ \\
\hline Dehydration & $1(4)$ & $4(20)$ & $5(23)$ & 0 & 0 & $3(15)$ & $13(11)$ \\
\hline
\end{tabular}

${ }^{a}$ MedDRA System Organ Class - includes rash maculo-papular $(n=20,17 \%)$, rash macular, rash pruritic (each $\left.n=15,13 \%\right)$, rash papular $(n=12,10 \%)$, rash erythematous $(n=11,9 \%)$, rash $(n=7,6 \%)$, pruritus $(n=5,4 \%)$, dermatitis acneiform, dry skin (each $n=2,2 \%)$, alopecia, circumoral edema, erythema nodosum, exfoliative rash, night sweats, petechiae, skin exfoliation, skin hyperpigmentation, swelling face, and urticaria (each $n=1,<1 \%$ ). Patients could have reported $>1 \mathrm{AE}$

${ }^{\mathrm{b}}$ High-level term, Peripheral neuropathies NEC - includes neuropathy peripheral and peripheral sensory neuropathy

$A E$ adverse event, $H \& N$ head and neck cancer, $M T D$ maximum tolerated dose, $N E C$ not elsewhere classified, NSCLC non-small cell lung cancer, $P C$ prostate cancer, $S C$ subcutaneous, STS soft tissue sarcoma, TPEC tumor pharmacodynamic expansion cohort

or oral antihistamines alone, and three received topical hydrocortisone. Ixazomib was discontinued permanently for one patient experiencing rash and periorbital edema; this rash resolved with concomitant medications.
Thrombocytopenia was the third most frequent drugrelated AE overall $(n=52,45 \%)$ and the most common drug-related grade $\geq 3 \mathrm{AE}(n=27,23 \%)$. Median platelet count appeared to decrease during ixazomib treatment

Table 3 The most common ( $\geq 3 \%$ of patients overall) drug-related grade $\geq 3$ AEs, overall and within the dose-escalation and expansion cohorts

\begin{tabular}{|c|c|c|c|c|c|c|c|}
\hline \multirow[t]{2}{*}{ AE, $n(\%)$} & \multirow{2}{*}{$\begin{array}{l}\text { Dose-escalation cohort } \\
(n=23)\end{array}$} & \multicolumn{5}{|c|}{ MTD expansion cohorts $(n=93)$} & \multirow{2}{*}{$\begin{array}{l}\text { Total } \\
(N=116)\end{array}$} \\
\hline & & $\begin{array}{l}\text { NSCLC } \\
(n=20)\end{array}$ & $\begin{array}{l}\mathrm{H} \& \mathrm{~N} \\
(n=22)\end{array}$ & $\begin{array}{l}\text { STS } \\
(n=20)\end{array}$ & $\begin{array}{l}\mathrm{PC} \\
(n=11)\end{array}$ & $\begin{array}{l}\text { TPEC } \\
(n=20)\end{array}$ & \\
\hline Thrombocytopenia & $5(22)$ & $2(10)$ & $7(32)$ & $3(15)$ & $3(27)$ & $7(35)$ & $27(23)$ \\
\hline Skin and SC tissue disorders ${ }^{\mathrm{a}}$ & $2(9)$ & $4(20)$ & $4(18)$ & $5(25)$ & $2(18)$ & $1(5)$ & $18(16)$ \\
\hline Fatigue & $1(4)$ & $1(5)$ & $2(9)$ & $2(10)$ & $2(18)$ & $3(15)$ & $11(9)$ \\
\hline Dehydration & $1(4)$ & $1(5)$ & $3(14)$ & 0 & 0 & $2(10)$ & $7(6)$ \\
\hline Lymphopenia & 0 & $1(5)$ & $1(5)$ & $1(5)$ & 0 & $3(15)$ & $6(5)$ \\
\hline Anemia & 0 & $2(10)$ & 0 & 0 & 0 & $1(5)$ & $3(3)$ \\
\hline Decreased platelet count & 0 & $2(10)$ & 0 & $1(5)$ & 0 & 0 & $3(3)$ \\
\hline Dyspnea & 0 & $1(5)$ & $1(5)$ & 0 & $1(9)$ & 0 & $3(3)$ \\
\hline Nausea & $1(4)$ & 0 & $1(5)$ & 0 & 0 & $1(5)$ & $3(3)$ \\
\hline $\begin{array}{l}\text { Peripheral neuropathies } \\
\text { NEC }^{\mathrm{b}}\end{array}$ & $1(4)$ & 0 & 0 & 0 & $1(9)$ & $1(5)$ & $3(3)$ \\
\hline Vomiting & $1(4)$ & 0 & 0 & $1(5)$ & 0 & $1(5)$ & $3(3)$ \\
\hline
\end{tabular}

${ }^{a}$ MedDRA System Organ Class - includes rash maculo-papular $(n=8,7 \%)$, rash macular $(n=3,3 \%)$, rash $(n=1,<1 \%)$, rash pruritic $(n=4,3 \%)$, rash erythematous $(n=2,2 \%)$, erythema nodosum, and rash papular (each $n=1,<1 \%$ ). Patients could have reported $>1 \mathrm{AE}$

${ }^{\mathrm{b}}$ High-level term, Peripheral neuropathies NEC - includes neuropathy peripheral and peripheral sensory neuropathy

$A E$ adverse event, $H \& N$ head and neck cancer, $M T D$ maximum tolerated dose, $N E C$ not elsewhere classified, NSCLC non-small cell lung cancer, $P C$ prostate cancer, SC subcutaneous, STS soft tissue sarcoma, TPEC tumor pharmacodynamic expansion cohort 


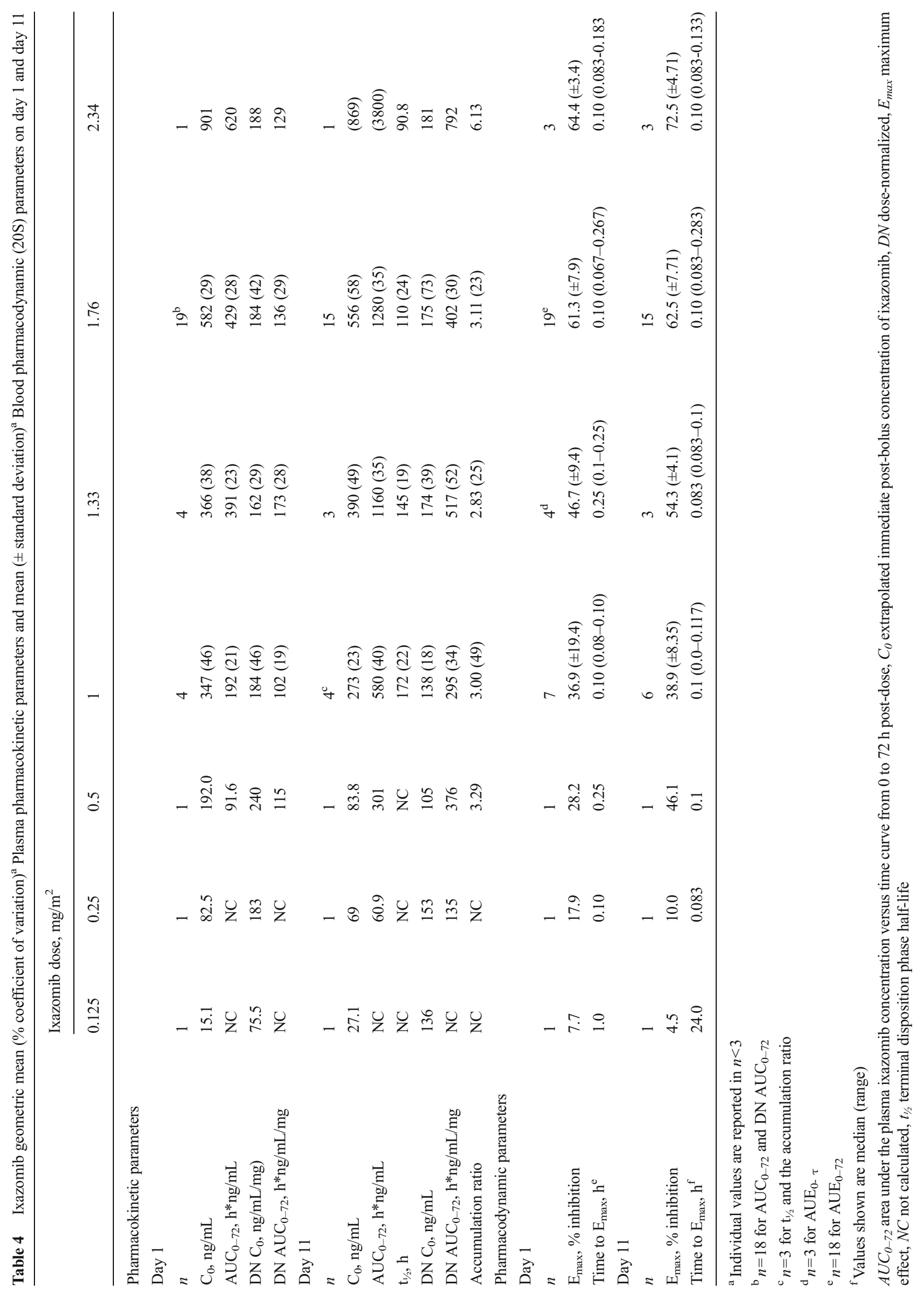


followed by recovery during the rest period of each cycle (data not shown). In total, five (4\%) patients required platelet transfusions. Drug-related PN NEC (not elsewhere classified; highlevel term that included neuropathy peripheral and peripheral sensory neuropathy) was reported in 17 patients $(15 \%)$. Most cases were grade $1(n=6)$ or grade $2(n=8)$ in intensity. Grade 3 PN NEC occurred in three patients ( $3 \%$ ), all of whom were receiving the MTD; one had grade 1 neuropathy at screening.

Seventeen patients $(15 \%)$ discontinued ixazomib due to treatment-emergent AEs. In the dose-escalation cohort, one non-DLT-evaluable patient receiving ixazomib $1.0 \mathrm{mg} / \mathrm{m}^{2}$ discontinued due to disease progression considered unrelated to ixazomib, one patient receiving $1.76 \mathrm{mg} / \mathrm{m}^{2}$ discontinued due to the DLT of drug-related pruritic rash, and one patient receiving $2.34 \mathrm{mg} / \mathrm{m}^{2}$ discontinued due to the DLT of drugrelated acute renal failure. In the NSCLC MTD expansion cohort, four patients discontinued due to: grade 3 pneumonia considered unrelated to ixazomib $(n=1)$; drug-related grade 3 pneumonitis $(n=1)$; drug-related grade 3 acute renal failure and grade 4 thrombocytopenia $(n=1)$; and drug-related grade 2 pruritic rash and grade 2 periorbital edema $(n=1)$. In the head and neck cancer cohort, five patients discontinued due to: grade 3 dyspnea $(n=1)$; grade 2 confusional state $(n=1)$; grade 5 obstructive pneumonia secondary to progressive cancer $(n=1)$; grade 5 squamous cell carcinoma $(n=1)$; and grade $2 \mathrm{PN}(n=1)$. Of these five AEs leading to discontinuation, only grade 3 dyspnea was considered treatment-related. In the soft tissue sarcoma cohort, two patients discontinued due to drug-related grade 3 pneumonitis $(n=1)$ and drug-related grade 3 fatigue $(n=1)$. In the prostate cancer cohort, two patients discontinued due to drug-related grade 3 ileus $(n=1)$ and drug-related grade $3 \mathrm{PN}(n=1)$. Lastly, one patient in the TPEC discontinued due to grade 4 brain metastases considered unrelated to ixazomib.

Drug-related serious AEs were seen in 32 patients (28\%). The most common ( $>2$ patients overall) of these events were thrombocytopenia $(n=7,6 \%)$, nausea, vomiting and dehydration (each $n=4,3 \%$ ), and fatigue $(n=3,3 \%)$. There were seven on-study deaths. Five patients died due to progressive disease, one due to obstructive pneumonia secondary to progressive cancer (as noted above), and one due to acute renal insufficiency and hypotension. None of the deaths was considered treatment-related.

\section{Pharmacokinetics and pharmacodynamics}

In total, 32 and 36 patients were included in the pharmacokinetic and pharmacodynamic (20S blood assay) populations, respectively. The key pharmacokinetic and pharmacodynamic parameters determined for these two populations are listed in Table 4.

Mean plasma concentrations of ixazomib decreased by approximately $90 \%$ during the initial rapid disposition phase, which lasted for approximately $8 \mathrm{~h}$ (Fig. 1a). The decline in plasma concentrations was then more gradual during the subsequent slow disposition phase (Fig. 1a), with the terminal half-life of ixazomib ranging from 3.8 to 7.2 days. Ixazomib plasma exposure appeared to increase proportionally with increasing ixazomib dose (from 0.5 to $2.34 \mathrm{mg} / \mathrm{m}^{2}$ ) (Fig. $1 \mathrm{~b}$ and Fig. S1). At the $1.76 \mathrm{mg} / \mathrm{m}^{2} \mathrm{MTD}$, exposures appeared similar across the expansion cohorts. Accumulation of ixazomib was approximately 3 -fold following the day 11 dose (Fig. 1c and Fig. S1).

Inhibition of $20 \mathrm{~S}$ proteasome in whole blood was immediate (Fig. S2), and maximal inhibition correlated with maximum plasma concentration. At the MTD of $1.76 \mathrm{mg} / \mathrm{m}^{2}$, an average maximal inhibition of $20 \mathrm{~S}$ proteasome activity of $60 \%$ was observed. In general, activity recovered to predose levels within $24 \mathrm{~h}$ following single-dose administration on day 1 (Fig. S2) with the notable exception of patients treated at the dose level greater than the MTD.

For the drug distribution and ATF-3 IHC analyses, tumor biopsies were collected from all 20 patients in the TPEC. Paired pre- and post-dose biopsies of sufficient size were considered evaluable for pharmacokinetic analysis from 10 patients; ixazomib was present in all 10 post-dose biopsies analyzed. Tumor pairs from seven patients (five with colorectal cancer, one with sarcoma, and one with adrenal cancer) passed quality control by standard hematoxylin and eosin staining for tumor content, and were evaluable for ATF-3 IHC. Six of the seven paired samples showed a statistically significant increase in post-dose ATF-3 levels $(p<0.05)$ (Fig. 2).

\section{Response to treatment}

Ninety-two patients received $\geq 1$ cycle of ixazomib treatment, had measurable disease at baseline, and had $\geq 1$ post-baseline response assessment, and therefore were included in the response-evaluable population. Twenty-four patients were not evaluable for response due to not completing at least $1 \mathrm{cy}$ cle of ixazomib treatment $(n=12)$, not having measurable disease at baseline $(n=2)$, or due to an absence of post-baseline response assessment $(n=10)$. A partial response was observed in one patient with head and neck cancer. This response was achieved after 4 cycles and was maintained for 8 cycles (total duration, 6.7 months). Stable disease was recorded for 30 patients, including eight with stable disease lasting for $\geq 4$ cycles. Among these eight patients, two were in the doseescalation cohort, three were in the NSCLC cohort, one was in the head and neck cancer cohort and two were in the soft tissue sarcoma cohort. Measurable tumor reduction was

Fig. 1 a Mean plasma concentration-time profiles for ixazomib on day 1 (top panel; $n=31$ ) and day 11 (bottom panel; $n=26$ ) of dosing, by dose level, and $\mathbf{b}$ geometric mean ( $\%$ coefficient of variance) $\mathrm{C}_{\max }$ and $\mathbf{c} \mathrm{AUC}$ of ixazomib on day 1 and day 11 of dosing, by dose level $(n=23)$ 

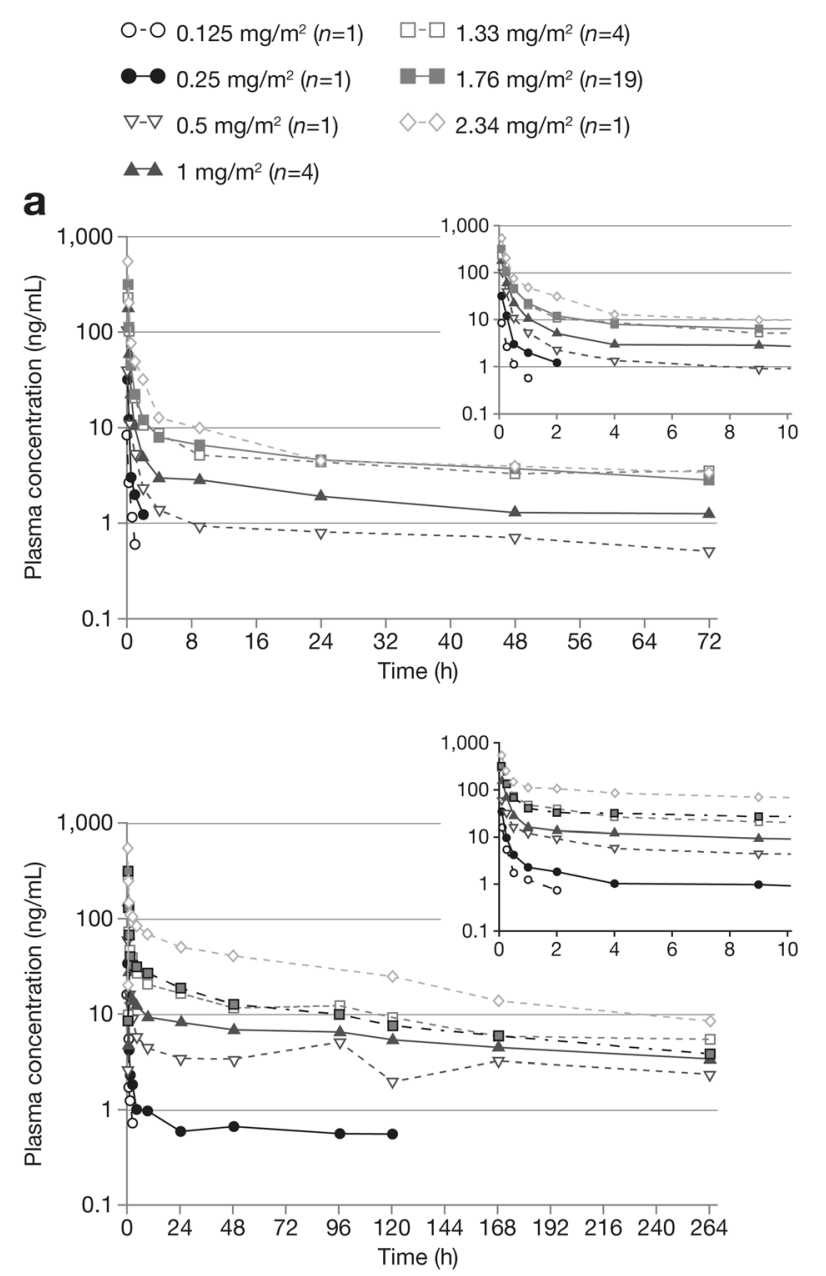

b

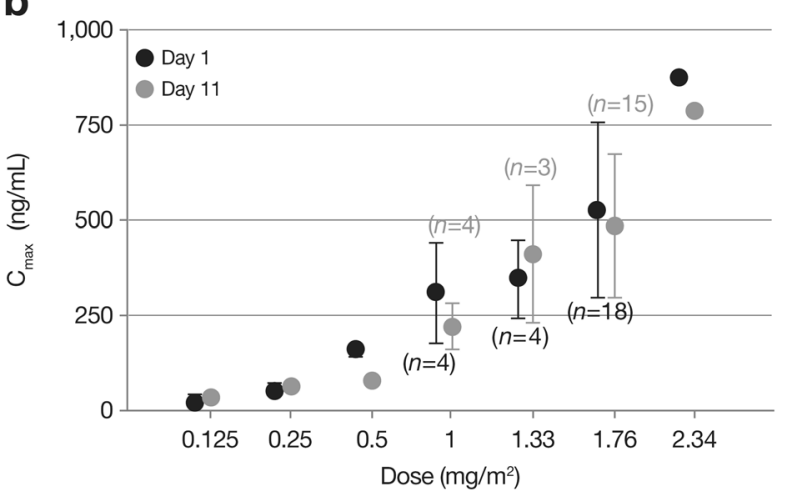

C

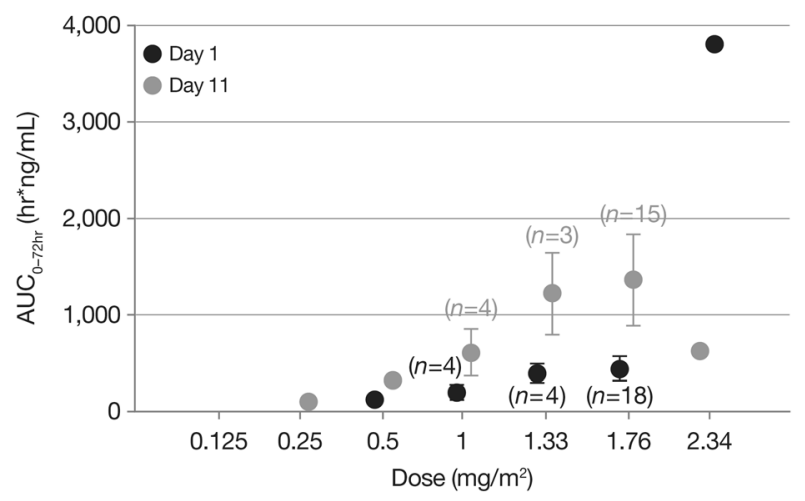

observed in two patients with kidney malignancies. One had a $14 \%$ reduction in tumor diameter; at the end of the study, their status was progressive disease with new lesions. The other had a $22 \%$ reduction in tumor diameter but discontinued from the study due to grade 3 acute renal failure.

\section{Discussion}

This first-in-human phase 1 study met its goal of defining the MTD and assessing safety of the investigational proteasome inhibitor ixazomib in patients with a spectrum of solid tumor types. The MTD for IV ixazomib on a twice-weekly schedule was established as $1.76 \mathrm{mg} / \mathrm{m}^{2}$. Treatment-related toxicities included fatigue, thrombocytopenia, gastrointestinal toxicities, and rash. The regimen was generally manageable and there was a low incidence of PN, which is consistent with observations from other studies evaluating ixazomib in patients with hematologic malignancies [26-29]. The pharmacodynamic investigations demonstrated dose-dependent $20 \mathrm{~S}$ proteasome inhibition in blood. Dose limiting toxicity appeared to be associated with a prolonged duration of $20 \mathrm{~S}$ proteasome inhibition in patients treated at the dose level above the MTD, although the number of patients treated is too small to make any definitive correlation. The study also provided evidence of target engagement in tumor tissue during treatment through the increase in ATF-3 expression in post-dose tumor samples. ATF-3 is a marker of unfolded protein response/endoplasmic reticulum stress, which is upregulated in response to proteasome inhibition [30-32]. The ATF3 data therefore represent the first pharmacodynamic evidence of proteasome pathway inhibition in solid tumors following ixazomib dosing. However, despite evidence of proteasome inhibition and pathway effects, IV ixazomib demonstrated only limited antitumor activity in these study patients with advanced non-hematologic malignancies. This is consistent with reports that pharmacological response is not a guarantee of a significant clinical response [33, 34]. Measurement of drug effect at the tumor site provides direct evidence that the drug has reached its target. ATF-3 upregulation has been widely observed in preclinical experiments conducted in more than 15 xenograft tumors treated with ixazomib; however, not all these xenograft models show tumor growth inhibition in response to ixazomib, and therefore it serves as a pharmacodynamic marker and not a predictor of efficacy even in preclinical models (data not shown).

The five DLTs reported with IV twice-weekly ixazomib included two cases of grade 3 pruritic rash reported at or below the MTD, grade 3 and 4 thrombocytopenia, and grade 3 acute renal failure seen at $2.34 \mathrm{mg} / \mathrm{m}^{2}$, the dose level above the MTD. The overall toxicity profile observed in this study was similar to those previously reported in other clinical studies of oral ixazomib in MM and light-chain amyloidosis, and 
Fig. 2 a Activating transcription factor-3 (ATF-3) levels in seven paired pre- and post-dose tumor biopsies from patients in the tumor pharmacodynamic expansion cohort, b fold-change in ATF-3 levels post- versus pre-dose and statistical significance ( $t$-test) by patient, and c ATF-3 staining of pre- and post-dose tumor samples from one patient

of IV ixazomib in lymphoma (in which rash and hematologic AEs were the most common DLTs) [26-29].

Overall, AEs were manageable; common all-grade and grade $\geq 3$ toxicities included fatigue, thrombocytopenia, gastrointestinal toxicities, and skin toxicities, especially rash. Generally, AEs of rash were manageable with antihistamines or lowdose topical/oral corticosteroids (if they did not resolve spontaneously during the rest week of therapy), and were reversible in the majority of cases, while thrombocytopenia appeared to be cyclical and reversible, as reported in other studies of ixazomib $[27,29]$. Gastrointestinal toxicities tended to resolve with appropriate supportive therapy. Comparable to other studies of single-agent ixazomib [26-29], there was a low rate of treatment-related $\mathrm{PN}$, including $3 \%$ grade $\geq 3$ events, all at the MTD. This is in contrast to the rates seen with bortezomib, where $\mathrm{PN}$ is a more common toxicity [35], but it is similar to the low rates reported for carfilzomib [36, 37]. It should be noted, however, that patients received a median of 2 cycles of treatment, and only one-fifth of patients received 4 cycles or more. Therefore, this treatment exposure may not have permitted a comprehensive understanding of the safety and tolerability profile of IV ixazomib in patients with solid tumors.

This paper describes for the first time the pharmacokinetic profile of ixazomib in patients with solid tumors. The pharmacokinetic analysis showed that ixazomib plasma concentrations decreased by approximately $90 \%$ within the first $8 \mathrm{~h}$ post-dose and the terminal half-life ranged from 3.8 to 7.2 days following multiple dosing, similar to results seen in patients with MM [29]. Additionally, across the full range of doses tested $\left(0.5\right.$ to $\left.2.34 \mathrm{mg} / \mathrm{m}^{2}\right)$, plasma exposure appeared to increase proportionally with increasing dose, and this did not differ markedly among patients with different tumor types. Current studies are investigating the pharmacokinetic profile of ixazomib following oral dosing, which has been selected as the route of administration for further clinical development of ixazomib in patients with hematologic malignancies, where the drug shows substantial clinical activity [26-29].

The lack of clinical activity in the present study is comparable to observations from bortezomib and carfilzomib studies in advanced solid tumors [7-13, 38]. At the MTD of $1.76 \mathrm{mg} /$ $\mathrm{m}^{2}$, only one patient with head and neck cancer achieved a partial response with ixazomib treatment. The lack of efficacy may be due to suboptimal duration of target inhibition at tolerable doses, but clinical activity can depend on many factors in addition to target inhibition, such as treatment duration, toxicity, and patient selection. A better understanding of additional response determinants including degree and duration of a

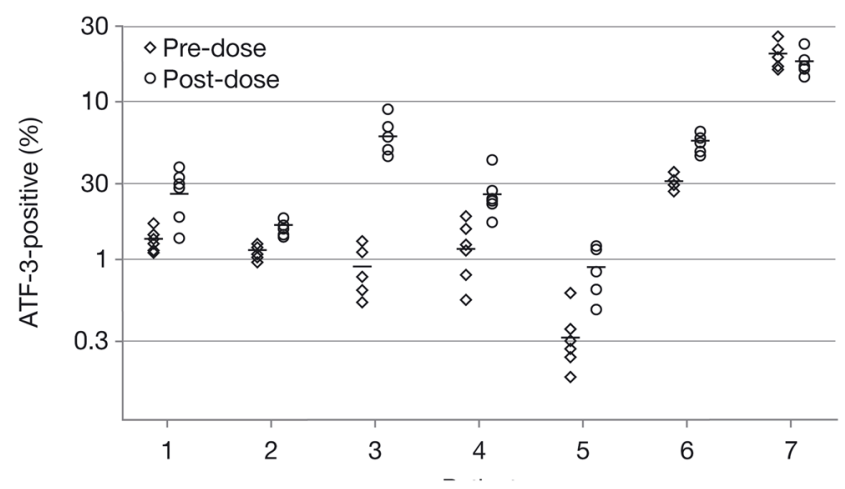

b

\begin{tabular}{|c|c|c|c|c|}
\hline Patient & $\begin{array}{c}\text { Fold } \\
\text { change }\end{array}$ & $p$-value & $90 \% \mathrm{Cl}$ & $\begin{array}{c}\text { Tumor } \\
\text { type }\end{array}$ \\
\hline 1 & 1.9 & 0.003 & $1.425-2.659$ & CRC \\
2 & 1.4 & $<0.001$ & $1.293-1.589$ & CRC \\
3 & 6.7 & $<0.001$ & $4.796-9.25$ & CRC \\
4 & 2.2 & 0.004 & $1.506-3.334$ & CRC \\
5 & 2.8 & 0.001 & $1.865-4.259$ & Adrenal \\
6 & 1.8 & $<0.001$ & $1.603-2.054$ & CRC \\
7 & 0.9 & 0.28 & $0.7456-1.068$ & Sarcoma \\
\hline
\end{tabular}

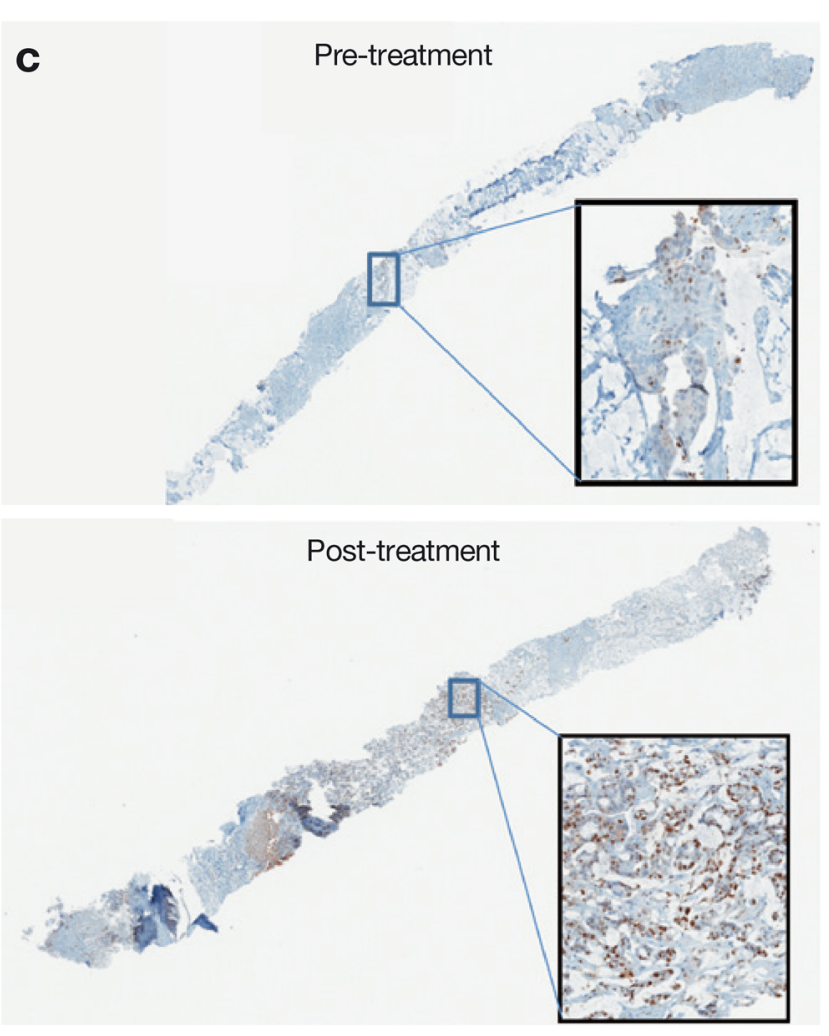


target inhibition is needed to improve outcomes in clinical studies investigating proteasome inhibitors. In conclusion, this study determined the safety profile, MTD, and pharmacokinetics and blood pharmacodynamics of IV ixazomib in patients with non-hematologic malignancies. Despite the demonstrated drug distribution and downstream effects of proteasome inhibition in solid tumor tissue, limited antitumor activity was observed in predefined tumor types, although it is of interest that one heavily pretreated patient with head and neck carcinoma experienced a durable response. Weekly oral ixazomib is currently being investigated in ongoing phase 3 trials in $\mathrm{MM}$ and primary systemic $\mathrm{AL}$ amyloidosis.

Acknowledgments The authors thank all patients included in this study and their families, as well as all physicians, research nurses, study coordinators, and research staff participating in the study. The authors would also like to acknowledge Michael J. Hanley of Takeda Pharmaceuticals International $\mathrm{Co}$ for the pharmacokinetic and pharmacodynamic data analysis, and Jane Saunders, a medical writer with FireKite, part of KnowledgePoint360, an Ashfield Company, for writing support during the development of this manuscript, which was funded by Millennium Pharmaceuticals, Inc. and complied with Good Publication Practice 2 ethical guidelines (Graf et al., BMJ 2009).

Conflict of interest David C. Smith received a grant from Millennium Pharmaceuticals Inc., a wholly owned subsidiary of Takeda Pharmaceutical Company Limited during the conduct of the study. Thea Kalebic is employed by Millennium Pharmaceuticals Inc., a wholly owned subsidiary of Takeda Pharmaceutical Company Limited. Jeffrey R. Infante has no disclosures. Lillian L. Siu has no disclosures. Daniel Sullivan has no disclosures. Gordana Vlahovic has no disclosures. John S. Kauh has no disclosures. Feng Gao, Allison J. Berger, Stephen Tirrell, Neeraj Gupta, Alessandra Di Bacco, Deborah Berg, Guohui Liu, Jianchang Lin, and AiMin Hui are employed by Millennium Pharmaceuticals Inc., a wholly owned subsidiary of Takeda Pharmaceutical Company Limited. John A. Thompson has no disclosures.

Financial support This study was funded by Takeda Pharmaceuticals International Co.

Authorship contributions DCS, JAT, TK, AJB, NG, ADB, DB, and $\mathrm{AMH}$ designed and/or performed the research reported in this analysis; DCS, JRI, LLS, DS, GV, JSK, FG, AJB, ST, NG, ADB, and JAT collected data; DCS, TK, FG, AJB, ST, NG, ADB, DB, GL, JL, AMH, and JAT analyzed and interpreted the data; and DCS wrote the manuscript. All authors reviewed and approved the manuscript.

Open Access This article is distributed under the terms of the Creative Commons Attribution License which permits any use, distribution, and reproduction in any medium, provided the original author(s) and the source are credited.

\section{References}

1. Ciechanover A, Schwartz AL (1998) The ubiquitin-proteasome pathway: the complexity and myriad functions of proteins death. Proc Natl Acad Sci U S A 95(6):2727-2730
2. Hershko A (2005) Early work on the ubiquitin proteasome system, an interview with Avram Hershko. Interview by CDD. Cell Death Differ 12(9):1158-1161

3. McBride A, Ryan PY (2013) Proteasome inhibitors in the treatment of multiple myeloma. Expert Rev Anticancer Ther 13(3):339-358

4. Moreau P, Richardson PG, Cavo M, Orlowski RZ, San Miguel JF, Palumbo A, Harousseau JL (2012) Proteasome inhibitors in multiple myeloma: 10 years later. Blood 120(5):947-959

5. Orlowski RZ, Kuhn DJ (2008) Proteasome inhibitors in cancer therapy: lessons from the first decade. Clin Cancer Res 14(6):1649-1657

6. Reinstein E, Ciechanover A (2006) Narrative review: protein degradation and human diseases: the ubiquitin connection. Ann Intern Med 145(9):676-684

7. Aghajanian C, Soignet S, Dizon DS, Pien CS, Adams J, Elliott PJ, Sabbatini P, Miller V, Hensley ML, Pezzulli S, Canales C, Daud A, Spriggs DR (2002) A phase I trial of the novel proteasome inhibitor PS341 in advanced solid tumor malignancies. Clin Cancer Res 8(8): 2505-2511

8. Blaney SM, Bernstein M, Neville K, Ginsberg J, Kitchen B, Horton T, Berg SL, Krailo M, Adamson PC (2004) Phase I study of the proteasome inhibitor bortezomib in pediatric patients with refractory solid tumors: a Children's Oncology Group study (ADVL0015). J Clin Oncol 22(23):4804-4809

9. Davis NB, Taber DA, Ansari RH, Ryan CW, George C, Vokes EE, Vogelzang NJ, Stadler WM (2004) Phase II trial of PS-341 in patients with renal cell cancer: a University of Chicago phase II consortium study. J Clin Oncol 22(1):115-119

10. Hamilton AL, Eder JP, Pavlick AC, Clark JW, Liebes L, GarciaCarbonero R, Chachoua A, Ryan DP, Soma V, Farrell K, Kinchla N, Boyden J, Yee H, Zeleniuch-Jacquotte A, Wright J, Elliott P, Adams J, Muggia FM (2005) Proteasome inhibition with bortezomib (PS-341): a phase I study with pharmacodynamic end points using a day 1 and day 4 schedule in a 14-day cycle. J Clin Oncol 23(25): $6107-6116$

11. Kondagunta GV, Drucker B, Schwartz L, Bacik J, Marion S, Russo P, Mazumdar M, Motzer RJ (2004) Phase II trial of bortezomib for patients with advanced renal cell carcinoma. J Clin Oncol 22(18): 3720-3725

12. Papandreou CN, Daliani DD, Nix D, Yang H, Madden T, Wang X, Pien CS, Millikan RE, Tu SM, Pagliaro L, Kim J, Adams J, Elliott P, Esseltine D, Petrusich A, Dieringer P, Perez C, Logothetis CJ (2004) Phase I trial of the proteasome inhibitor bortezomib in patients with advanced solid tumors with observations in androgen-independent prostate cancer. J Clin Oncol 22(11):2108-2121

13. Shah MH, Young D, Kindler HL, Webb I, Kleiber B, Wright J, Grever M (2004) Phase II study of the proteasome inhibitor bortezomib (PS-341) in patients with metastatic neuroendocrine tumors. Clin Cancer Res 10(18 Pt 1):6111-6118

14. Mitsiades CS, McMillin D, Kotoula V, Poulaki V, McMullan C, Negri J, Fanourakis G, Tseleni-Balafouta S, Ain KB, Mitsiades N (2006) Antitumor effects of the proteasome inhibitor bortezomib in medullary and anaplastic thyroid carcinoma cells in vitro. J Clin Endocrinol Metab 91(10):4013-4021

15. Yin D, Zhou H, Kumagai T, Liu G, Ong JM, Black KL, Koeffler HP (2005) Proteasome inhibitor PS-341 causes cell growth arrest and apoptosis in human glioblastoma multiforme (GBM). Oncogene 24(3):344-354

16. Cusack JC (2003) Rationale for the treatment of solid tumors with the proteasome inhibitor bortezomib. Cancer Treat Rev 29(Suppl):121131

17. Adams J, Palombella VJ, Sausville EA, Johnson J, Destree A, Lazarus DD, Maas J, Pien CS, Prakash S, Elliott PJ (1999) Proteasome inhibitors: a novel class of potent and effective antitumor agents. Cancer Res 59(11):2615-2622

18. Schenkein DP (2005) Preclinical data with bortezomib in lung cancer. Clin Lung Cancer 7(2):S49-S55 
19. Dick LR, Fleming PE (2010) Building on bortezomib: secondgeneration proteasome inhibitors as anti-cancer therapy. Drug Discov Today 15(5-6):243-249

20. Kupperman E, Lee EC, Cao Y, Bannerman B, Fitzgerald M, Berger A, Yu J, Yang Y, Hales P, Bruzzese F, Liu J, Blank J, Garcia K, Tsu C, Dick L, Fleming P, Yu L, Manfredi M, Rolfe M, Bolen J (2010) Evaluation of the proteasome inhibitor MLN9708 in preclinical models of human cancer. Cancer Res 70(5):1970-1980

21. Chauhan D, Tian Z, Zhou B, Kuhn D, Orlowski R, Raje N, Richardson P, Anderson KC (2011) In vitro and in vivo selective antitumor activity of a novel orally bioavailable proteasome inhibitor MLN9708 against multiple myeloma cells. Clin Cancer Res 17(16): 5311-5321

22. Lee EC, Fitzgerald M, Bannerman B, Donelan J, Bano K, Terkelsen J, Bradley DP, Subakan O, Silva MD, Liu R, Pickard M, Li Z, Tayber O, Li P, Hales P, Carsillo M, Neppalli VT, Berger AJ, Kupperman E, Manfredi M, Bolen JB, Van NB, Janz S (2011) Antitumor activity of the investigational proteasome inhibitor MLN9708 in mouse models of B-cell and plasma cell malignancies. Clin Cancer Res 17(23): 7313-7323

23. Therasse P, Arbuck SG, Eisenhauer EA, Wanders J, Kaplan RS, Rubinstein L, Verweij J, Van GM, van Oosterom AT, Christian MC, Gwyther SG (2000) New guidelines to evaluate the response to treatment in solid tumors. European Organization for Research and Treatment of Cancer, National Cancer Institute of the United States, National Cancer Institute of Canada. J Natl Cancer Inst 92(3):205216

24. Scher HI, Halabi S, Tannock I, Morris M, Sternberg CN, Carducci MA, Eisenberger MA, Higano C, Bubley GJ, Dreicer R, Petrylak D, Kantoff P, Basch E, Kelly WK, Figg WD, Small EJ, Beer TM, Wilding G, Martin A, Hussain M (2008) Design and end points of clinical trials for patients with progressive prostate cancer and castrate levels of testosterone: recommendations of the Prostate Cancer Clinical Trials Working Group. J Clin Oncol 26(7):1148-1159

25. Lightcap ES, McCormack TA, Pien CS, Chau V, Adams J, Elliott PJ (2000) Proteasome inhibition measurements: clinical application. Clin Chem 46(5):673-683

26. Assouline S, Chang JE, Cheson BD, Rifkin R, Hamburg S, Reyes R, Hui A-M, Gupta N, Di Bacco A, Shou Y, Martin P (2012) Results of a phase 1 dose-escalation study of once-weekly MLN9708, an investigational proteasome inhibitor, in patients with relapsed/refractory lymphoma (Abstract). Blood 120:3646

27. Kumar SK, Bensinger WI, Zimmerman TM, Reeder CB, Berenson JR, Berg D, Hui AM, Gupta N, Di BA, Yu J, Shou Y, Niesvizky R (2014) Phase 1 study of weekly dosing with the investigational oral proteasome inhibitor ixazomib in relapsed/refractory multiple myeloma. Blood 124(7):1047-1055

28. Merlini G, Sanchorawala V, Zonder JA, Kukreti V, Schonland SO, Jaccard A, Dispenzieri A, Cohen AD, Berg D, Liu G, Di Bacco A, Gupta N, Hui A-M, Palladini G, Comenzo RL (2012) MLN9708, a novel, investigational oral proteasome inhibitor, in patients with relapsed or refractory light-chain amyloidosis (AL): results of a phase 1 study (Abstract). Blood 120:731
29. Richardson PG, Baz R, Wang M, Jakubowiak AJ, Laubach JP, Harvey RD, Talpaz M, Berg D, Liu G, Yu J, Gupta N, Di BA, Hui AM, Lonial S (2014) Phase 1 study of twice-weekly ixazomib, an oral proteasome inhibitor, in relapsed/refractory multiple myeloma patients. Blood 124(7):1038-1046

30. Jiang HY, Wek SA, McGrath BC, Lu D, Hai T, Harding HP, Wang X, Ron D, Cavener DR, Wek RC (2004) Activating transcription factor 3 is integral to the eukaryotic initiation factor 2 kinase stress response. Mol Cell Biol 24(3):1365-1377

31. Pan Y, Chen H, Siu F, Kilberg MS (2003) Amino acid deprivation and endoplasmic reticulum stress induce expression of multiple activating transcription factor-3 mRNA species that, when overexpressed in HepG2 cells, modulate transcription by the human asparagine synthetase promoter. J Biol Chem 278(40):38402-38412

32. Zimmermann J, Erdmann D, Lalande I, Grossenbacher R, Noorani M, Furst P (2000) Proteasome inhibitor induced gene expression profiles reveal overexpression of transcriptional regulators ATF3, GADD153 and MAD1. Oncogene 19(25):2913-2920

33. Zhou Q, Gallo JM (2011) The pharmacokinetic/pharmacodynamic pipeline: translating anticancer drug pharmacologyto the clinic. AAPS J 13(1):111-120

34. Keizer RJ, Schellens JHM, Beijnen JH, Huitema ADR (2011) Pharmacodynamic biomarkers in model-based drug development in oncology. Curr Clin Pharmacol 6(1):30-40

35. Richardson PG, Delforge M, Beksac M, Wen P, Jongen JL, Sezer O, Terpos E, Munshi N, Palumbo A, Rajkumar SV, Harousseau JL, Moreau P, Avet-Loiseau H, Lee JH, Cavo M, Merlini G, Voorhees P, Chng WJ, Mazumder A, Usmani S, Einsele H, Comenzo R, Orlowski R, Vesole D, Lahuerta JJ, Niesvizky R, Siegel D, Mateos MV, Dimopoulos M, Lonial S, Jagannath S, Blade J, Miguel JS, Morgan G, Anderson KC, Durie BG, Sonneveld P (2012) Management of treatment-emergent peripheral neuropathy in multiple myeloma. Leukemia 26(4):595-608

36. Siegel DS, Martin T, Wang M, Vij R, Jakubowiak AJ, Lonial S, Trudel S, Kukreti V, Bahlis N, Alsina M, Chanan-Khan A, Buadi F, Reu FJ, Somlo G, Zonder J, Song K, Stewart AK, Stadtmauer E, Kunkel L, Wear S, Wong AF, Orlowski RZ, Jagannath S (2012) A phase 2 study of single-agent carfilzomib (PX-171-003-A1) in patients with relapsed and refractory multiple myeloma. Blood 120(14): 2817-2825

37. Vij R, Wang M, Kaufman JL, Lonial S, Jakubowiak AJ, Stewart AK, Kukreti V, Jagannath S, McDonagh KT, Alsina M, Bahlis NJ, Reu FJ, Gabrail NY, Belch A, Matous JV, Lee P, Rosen P, Sebag M, Vesole DH, Kunkel LA, Wear SM, Wong AF, Orlowski RZ, Siegel DS (2012) An open-label, single-arm, phase 2 (PX-171-004) study of single-agent carfilzomib in bortezomib-naive patients with relapsed and/or refractory multiple myeloma. Blood 119(24):5661-5670

38. Papadopoulos KP, Burris HA III, Gordon M, Lee P, Sausville EA, Rosen PJ, Patnaik A, Cutler RE Jr, Wang Z, Lee S, Jones SF, Infante JR (2013) A phase I/II study of carfilzomib 2-10-min infusion in patients with advanced solid tumors. Cancer Chemother Pharmacol 72(4):861-868 